\title{
Appraising and reappraising of compliments and the provision of responses
}

\section{Automatic and non-automatic reactions}

\author{
Mostafa Morady Moghaddam \\ Shahrood University of Technology
}

The role of cognitive processes in compliment-response (CR) exchanges is an underdeveloped area of investigation. This article aims to probe whether Persian speakers' responses to compliments change in line with their appraisals of the situation. To achieve this aim, Persian speakers' responses to compliments are analysed based on their first and second appraisals of the event. In this study, with a focus on the CR exchanges, Persian speakers $(N=160)$ were observed and audio-recorded during everyday conversation. The results of this study manifest that Persian speakers have distinct (and even opposite) reactions based on their first and second appraisal of compliments. This suggests, therefore, that Appraisal 1 and Appraisal 2 undergo different sociocognitive processes that reflect automatic and non-automatic responses to compliments. It is concluded that the relation between Appraisal 1 and Appraisal 2 is mostly contradictory rather than confirmatory, in that the first compliment is mostly appraised as a politeness strategy (a social lubricant), whereas the second compliment is frequently appraised as purposeful or strategic praise. In addition, the first compliment is responded to automatically, whereas the second compliment is approached non-automatically.

Keywords: appraisal, compliment responses, Persian speakers, pragmatics, speech acts

\section{Introduction}

Compliments have been addressed in different ways. In line with Holmes $(1988,446)$, complimenting is "a speech act which explicitly or implicitly attributes credit to someone other than the speaker, usually the person addressed, for some 'good' ... which is positively valued by the speaker and the hearer.' Nkwain 
$(2011,61)$, likewise, defines compliments as "a positive politeness strategy that expresses goodwill and solidarity between interlocutors, although compliments tend to serve other functions, depending on the interpretation they are coded." These two definitions, albeit interesting, underestimate the intricacies of the compliment-response (CR) exchanges. These constructs are complicated social events (Ansarin and Morady Moghaddam 2016), cases of intricate language games' (to use the terminology by Wittgenstein 1953), and 'forms of life', which are manufactured during the interaction in line with contextual/situational clues. Compliments are situated speech acts or pragmemes, according to Mey's (2001) Pragmatic Act Theory. Mey states that "[s]peech acts, in order to be effective, have to be situated" $(2001,219)$. By situated, it means we should deal with them based on the dynamics of interaction.

Compliments do not have a fixed function in the interaction. Compliment speech acts are, thus, speech events that are guided by Principles of Probability (Weigand 2010), suggesting that no fixed rules govern them (as is the case for all speech acts, not only complimenting). The bulk of research done on the $\mathrm{CR}$ exchanges clearly proves that they are complicated acts which deserve consideration of the dynamics of the situation to decode the (in)sincerity of the explicature. That said, it is not only the decoding and encoding of compliment exchanges that lead to byzantine language behaviour. Compliments can play different roles in conversation, such as a politeness strategy, ${ }^{1}$ phatic communication, request, and so forth.

Therefore, one reason why compliments have not a fixed function is the way they have been conceptualised by individuals during the interaction. More often than not, compliments and their responses are conceptualised based on societal factors, while issues such as cognitive processes (such as judgements, emotion, and expectations) are rarely considered in research studies. Judgements or appraisals ${ }^{2}$ of a situation, for example, can shape the way individuals react to compliments. Appraisal theories argue that the individual's judgement of an event is the benchmark that shapes their emotion (Roseman and Smith 2001). On this account, appraisal theories advocate a cognitively-mediated view of emotion that forces individuals to behave in a certain way. As reported by Scarantino $(2016,21)$, "[a]n important qualification is that, in the case of basic emotions, an appraisal process mediates between the stimulus and the cascade of responses." Appraisals, therefore, can alter the illocutionary force (the intended meaning) of a response.

1. By politeness, I mean considering positive face wants of the interlocutors.

2. Appraisal theorists believe that "emotions are elicited by evaluations (appraisals) of events and situations" (Roseman and Smith 2001,3). 
It is logical to claim that speech acts are governed by factors beyond social conventions. In the same vein, Weigand (2010) advocates that 'New Science' moves towards holism, which takes into consideration "the complex whole as a hierarchy of interacting subsystems, among them human abilities such as speech, perception and thought" (Weigand 2010,5). This indicates that to see the compliment speech act merely based on the constraints of the social context is an underestimation of this complexity. Complimenting should be analysed based on a sociocognitive framework, one that not only takes into consideration cultural conventions but also deals with and is anchored in judgements, experiences, and emotions. Accordingly, there is the need for a more holistic view on compliments as a situationally, culturally, and cognitively embedded speech act. By highlighting the role of automatic and non-automatic processes in responding to compliments, I intend to make a distinction between these two processes as the way Schneider and Shiffrin $(1984,269)$ conceptualise automatic and controlled processes:

Automatic processing is generally a fast, parallel, fairly effortless process that is not limited by short-term memory capacity, is not under direct subject control, and performs well-developed skilled behaviors. [...] Controlled processing is often slow, generally serial, effortful, capacity-limited, subject-regulated, and is used to deal with novel or inconsistent information. [...] all tasks are carried out by complex mixtures of controlled and automatic processes used in combination.

On this account, according to Lombardi Vallauri $(2016,735)$ " $[t]$ he existence of means by which, in discourse, some information can be entrusted to automatic instead of controlled processing, is an obvious advantage in terms of effort economy." Consequently, when it is mentioned that uttering and grasping a compliment is a sociocognitive activity, it means that the practice is regulated by both automatic and controlled processes in line with Sperber and Wilson's (1986) 'principle of economy'. Conforming with Sperber and Wilson (1986, vii): "[h]uman cognitive processes, we argue, are geared to achieving the greatest possible cognitive effect for the smallest possible processing effort." Responses to compliments can be conceptualised based on the 'principle of economy' whereby the responses can be categorised in accord with the amount of cognitive effort required to provide a response to a compliment.

The impetus behind this study is to find out how individuals' judgements and emotions (cognitive aspects) would alter the way Persian speakers provide responses to compliments. Therefore, this article aims to investigate whether Persian speakers' responses to compliments change sympathetic towards their appraisals of the situation. If yes, how does the appraisal or judgement of the situation affect the provision of response? 
The objective of this study is to find out how cognitive processes such as judging and perceiving would alter the way interlocutors respond to compliments. Biases and background encounters with the complimenter can also be counted as important cognitive factors that play a key role in the picture. In what follows (Section 2), I will deal with studies done on Persian and other languages to provide background information and to facilitate comparison. In Section 3, I discuss the methodology of the research and explain how the data were gathered and codified. Section 4 is devoted to the analysis of the data based on the first and the second appraisal of compliment 1 and 2. Section 5 summarises the main findings and proposes the concept of 'emotional stance' as to discuss why the first response to the first compliment is different from the second response to the second compliment and so forth.

\section{Review of the literature}

Among the earliest studies on CR exchanges, Pomerantz's (1978) work is considered a yardstick for the subsequent research on compliment responses. The literature of complimenting is rich, and a great bulk of research exists on CR exchanges. The study on CRs has a long history, dating back to 1970s when the first known research on complimenting was done by Pomerantz (1978) on American-English CR strategies. Pomerantz (1978) proposed that American people were believed to respond directly to compliments by accepting praise, but she further verified that her data turned out to prove the opposite view of this general belief. She argued that "a large proportion of compliment responses deviate[d] from the model response of accepting compliments" (Pomerantz 1978, 81). On the other hand, in a follow-up study, Holmes (1988) criticised Pomerantz's (1978) research methodology and discussed that the New Zealanders' dominant CR strategy was to accept appraisals. She mentioned that in New Zealand, people rarely reject a compliment but female speakers accepted compliments much more than men did. Rejection was the least used strategy by both male and female speakers. Holmes (1988) confirmed that 'debt-sensitive' cultures (such as in Japan) would more probably reject a compliment. The pioneering studies done by Pomerantz (1978), Holmes (1988), and Herbert (1990) set the foundation for the vast majority of research done on the CR exchanges.

The foregoing studies provided the incentive for studies done on CR exchanges across different cultures. Some recent studies on compliments are acknowledged here, especially those that address languages other than English (or contexts other than the 'central' English speaking countries) as they provide counter-examples to primary accounts of compliments. Farghal and Al-Khatib 
(2001) investigated from a pragmatic and sociolinguistic perspective compliment responses among Jordanian Arabic performed by Jordanian college students. It was uncovered that Jordanian students favoured simple responses $(72.94 \%)$ much more than the complex ones $(27.06 \%)$. All in all, the macro-function of accepting compliments was observed more frequently (at 83.85\%), while male students accepted the compliments more often than female students.

Lorenzo-Dus (2001) investigated compliment responses with regard to positive and negative politeness among British and Spanish students. Two kinds of a Discourse Completion Test ${ }^{3}$ (DCT), one in Spanish and another in British, were used to elicit the data. The findings of the study revealed that British speakers favoured 'questioning the truth value of the compliments' more than their Spanish counterparts. It was argued that in Spanish culture, it was men who initiated the compliments to females and some strategies were used by women to let men appear dominant in conversation, which was not the case with British women. On this account, there was a male-dominant attitude in complimenting that shows the traditional gender relations in Spain.

To compare German and American compliment responses, Golato (2002) audio-taped some participants during a naturally-occurred conversation. A conversation-analysis methodology was utilised to examine the data. Golato $(2002,550)$ mentioned that "[a]lthough the most frequent response to a compliment in American English is not an acceptance, acceptances of compliments were frequently realized as appreciations." Appreciation tokens are the most commonly used CR strategy among American speakers. It was revealed that German speakers had a higher tendency to accept a compliment but there was a strikingly noticeable difference between the way American and German speakers accepted a compliment in that in German CR strategies there were no appreciation markers such as 'thank you'. Tang and Zhang (2009) conducted another study on CR strategies. The study tried to investigate the differences between Mandarin Chinese and Australian English speakers in the use of compliment response strategies. It was figured out that both Mandarin Chinese and Australian English speakers were inclined to use 'accept strategies' while following the same pattern of preferences regarding compliment responses. However, the main difference was

3. DCT is a data elicitation tool that is anchored in "the cooperation of informants who are asked to imagine communication situations and how they would behave in them" (Danziger 2018,76 ). The application of DCTs in pragmatics and discourse studies has not been without controversies. They have been criticised for their non-interactive nature (Bardovi-Harlig and Hartford 2005), excluding non-verbal features of communication (Kasper 2008), and inability to record subtle features of face-to-face conversations (Kasper 2008). 
that Mandarin Chinese speakers were more inclined to use indirect strategies than the explicit ones.

As related to Nigerian English, Mustapha (2011) investigated compliment responses of native speakers according to three different functions of compliments, i.e., supportive, attributive, and evaluative. Mustapha (2011) mentioned that there are different versions of thank you. Positive nonverbal, paralinguistic responses were used as a type of non-verbal acceptance. Moreover, praise upgrade including shift praise, scale down, and answer-question were classified as acceptance strategies. In responses to evaluative actions, participants agreed or disagreed with the compliments. Respondents agreed through using verbal and nonverbal signals such as smiling, as opposed to frowning and hissing (rejecting), modified agreement, and referent shift. For attributive action, acceptance was indicated through acceptance of credit, explicit acceptance, or reducing the credit. Rejection was manifested by shifting the credit, evading response, no response at all, topic change, and opting out. In supportive action, most of the speakers accepted the compliments (94\%). More recently, Danziger (2018) has done a study on Hebrew speakers' CR patterns. Using a DCT, Danziger realised that Hebrew speakers are more inclined to accept the compliments while the patterns observed among Hebrew speakers were claimed to be more diversified in comparison to other cultures.

Research on compliment speech act in Persian language lacks flexibility in terms of methodology and scope, yet fruitful in considering cross-cultural variations and social norms. Studies on CRs in Persian are mainly divided into those that use a DCT as a survey instrument, and those that resort to TV interview analysis. Convenience sampling is employed extensively in Iranian studies on the CR exchanges. The DCT is the most common method, having been used in a substantial number of studies on Persian CR exchanges. And almost all studies done on Persian compliments are anchored in the analysis of social factors of this specific speech act.

Sharifian (2005) conducted what is probably the first known research on the CR exchanges that employed a DCT to elicit responses from native Persian and Australian speakers. He found out that Persian speakers employ the schema of shekasteh-nafsi (modesty) in their responses to compliments. In line with Sharifian $(2005,337)$, "[t]he schema [shekasteh-nafsi] motivates the speakers to downplay their talents, skills, achievements, etc. while praising a similar trait in their interlocutors." Sharifian puts emphasis on the importance of cross-cultural miscommunication, by arguing that Persian speakers are mostly inclined to deny or downplay a compliment as a sign of modesty. On this account, shekasteh-nafsi is an important factor influencing the giving of compliments and responses to them within Iranian culture. Likewise, in a comprehensive study, Motaghi-Tabari 
and Beuzeville (2012) showed that native Persian speakers agree less with the illocutionary force of the compliments in comparison to Iranians in Australia or Australian-English speakers. A few studies have used TV interviews as their data gathering tool. For instance, Karimnia and Afghari (2011) found traces of shekasteh-nafsi in Iranian responses to compliments, which corresponds to a dominance of nonacceptance comments. They also suggest that most American speakers employ acceptance strategies in response to appraisals.

Contrary to Sharifian (2005) and his like-minded followers, Heidari and colleagues (2009) state that both Iranian male and female learners of English accept compliments elicited through a DCT. In addition, they highlight that female learners employ evade and reject strategies, and use fewer acceptance strategies. Likewise, Yousefvand (2010) claims that although native Persian speakers demonstrate the culturally valued schema of modesty in their responses by using formulaic expressions, they are more inclined to accept compliments (34.6\%) rather than applying nonacceptance (9.43\%) or nonagreement strategies $(24.82 \%)$. In the same vein, Razmjoo, Barabadi, and Arfa (2013) investigated Iranian compliment responses using the rejection/acceptance dimension system to categorise the data. They proved that the main strategy used by Persian speakers is to agree with a compliment.

Other researchers, on the other hand, have probed different aspects of complimenting which may be less relevant to the aim of this study, yet provide information about the scope of research on complimenting in the Iranian context. Conducting a study on Iranian EFL learners and Australian native speakers, Mohajernia and Solimani (2013) recognised that both EFL learners and Australians employ mitigation as the dominant CR strategy, although Iranian EFL learners accept compliments less often than Australian speakers. In another study, Allami and Montazeri (2012) explored the CRs of 40 Iranian EFL learners and uncovered that $50.7 \%$ of all responses fell into the category of acceptance, with appreciation tokens as the most frequently observed micro function (31.4\% of the total data). Likewise, Sadeghi and Zarei (2013) proved that Iranian EFL learners use similar strategies in both Persian and English DCTs. They argue that the dominant strategy among the learners is acceptance, while the least used strategy is rejection. Ansarin and Morady Moghaddam (2016) studied the complimenting functions among Iranian EFL learners and argued that explicit compliments are most favoured among participants, claiming that there are more similarities than differences between Iranian EFL learners and native English speakers regarding patterns of complimenting. They argue that advances in technology and the inclination of the younger generation towards Hollywood movies and international computer games have been some key issues in familiarising Iranian EFL learners with the norms of English speakers (the language of most well-known com- 
puter games is English). Recently, using naturally occurring talk in interaction, Morady Moghaddam (2017) investigated the extreme politeness strategies of Iranian women responding to compliments. He concluded that Iranian women apply five extreme responses based on their cultural norms and values. Likewise, he advocates complexities in the CR exchanges, suggesting that they are highly contextualised.

The studies done on Persian CR exchanges are not flexible with regard to methodology, and research regarding the CR patterns has clearly yielded conflicting results. With regard to methodology, the instrument and subjects' background have an important impact on the CR strategies. The younger generation in Iran has had more contact with the world in recent decades, and access to the norms and conventions of other cultures is easier because of the internet and various English textbooks available to students. With regard to scope, the review of the literature also showed that topics such as emotional stance, ${ }^{4}$ cognitive processing, and appraisals of compliments are not taken into consideration as important variables. The current study is different from previous research done on Persian CRs in three ways. First, this study uses observation and recording of everyday conversation as the data gathering tool. Therefore, the data are considered more representative of authentic talk. Second, this study considers a broader scope, employing a sociocognitive approach to the analysis of the CR exchanges, based on the tenets of appraisal theories of emotion. Third, in this study, subjects' second judgement of a second compliment is also investigated. It is well-acknowledged that compliments may be used as phatic communication (Rees-Miller 2011) or as a social lubricant (Maíz-Arévalo 2012), yet repeating the compliment later in the conversation means it must have a different purpose since friendliness has already been established and the conversation has opened up.

\section{Method}

The data were gathered as they occurred during the interaction (this method is unobtrusive and is more authentic in comparison to widely-used DCTs). A male research assistant (a thirty-year-old native Persian speaker) who was a $\mathrm{PhD}$ student in Linguistics was instructed on how to provide compliments. The researcher

4. Ochs $(1996,410)$ defines emotional stance as "a mood, attitude, feeling and disposition, as well as degrees of emotional intensity vis-a-vis some focus of concern." As advocated by Goodwin et al. $(2012,16)$, "[i]n the midst of doing things together, participants display how they align themselves toward other participants with whom they are interacting (as well as to their actions)." 
and the assistant interacted with each other face to face and discussed the research progress. The research assistant surreptitiously recorded the interactions on his mobile phone during personal conversation with his friends and classmates $(N=160)$. Every interaction took nearly 10 minutes (nearly 26 hours of interaction were recorded during a period of three months). The interactions occurred in Persian and in an informal style. The data were gathered in one of the following three places: the university campus, university restaurant and cafeteria. The author and the assistant discussed the transcriptions and the data were transcribed in IPA to provide the exact phonetic forms for readers who are not familiar with Persian alphabet. ${ }^{5}$

The topic of CRs (possession, ability, personality, appearance) and subjects' gender are not dealt with as variables in this study (but see Morady Moghaddam (2017) for an overview of the role of gender and topic in Persian compliment responses). In this study, I focus on the cognitive aspects of CR patterns by analysing whether the first appraisal of the first compliment is different from the second appraisal of the second compliment on the same topic. The research assistant was taught how to compliment his conversation partner(s) based on a particular compliment topic. The research assistant was required to compliment each person twice, re-praising the same compliment topic with a different syntax. The syntax of the first compliment $\left(\mathrm{C}_{1}\right)$ and the second (delayed) compliment $\left(\mathrm{C}_{2}\right)$ could be modified as long as their illocutionary force remained intact. The goal was to study the subjects' responses after $\mathrm{C}_{1}$ and $\mathrm{C}_{2}$. The research procedure was as follows:

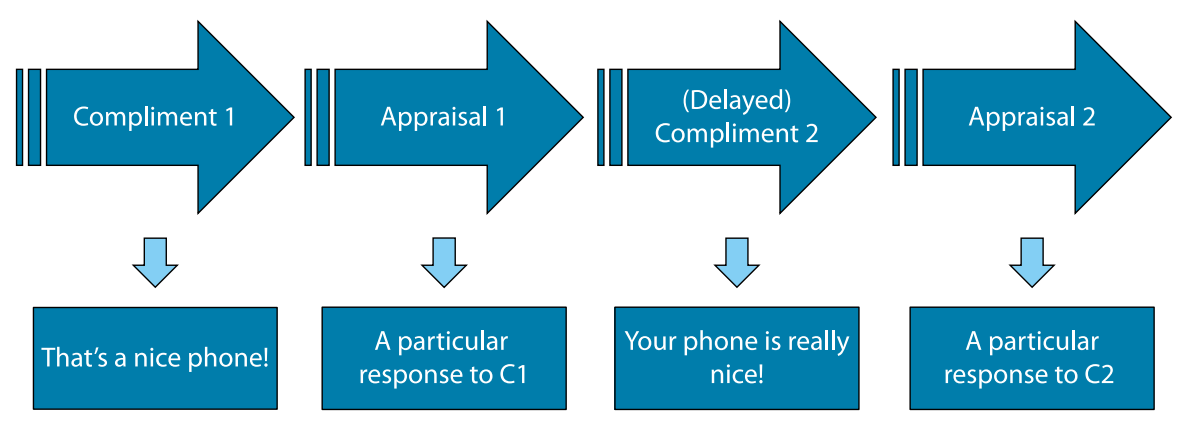

Figure 1. General structure of the study

As the scheme shows, after the research assistant compliments his conversation partner for the first time, the partner provides a particular response based

5. Refer to https://en.wikipedia.org/wiki/Help:IPA/Persian for an overview of the phonetic forms. 
on his/her appraisal of $\mathrm{C}$. The research assistant continues the conversation, and after a short delay, compliments his conversational partner for a second time on the same topic. Accordingly, the complimentee reacts to the delayed $\mathrm{C}_{2}$ based on his/her second appraisal of the event. In this way, it is possible to compare Appraisal 1 (A1) and Appraisal 2 ( $\left.\mathrm{A}_{2}\right)$ to examine whether there are any similarities or differences between them. The coding system used to categorise the data is linked with a five-scale category of acceptance, nonacceptance, nonagreement, request interpretation, and no acknowledgement. These categories are derived from Holmes (1988) and Herbert (1990). Both the researcher and the research assistant coded the data separately and Cronbach's alpha indicated the inter-rater reliability of $.79 .{ }^{6}$ The responses to compliments were transcribed by the assistant and the whole data were categorised by both the researcher and the assistant. If no consensus was reached between the researcher and the assistant, the response was shared with a second assistant to reach a consensus when coding the data.

\section{Results}

This section presents the analyses of the subjects' CR patterns based on the audiorecorded interactions. The aim is not only to provide frequencies and percentages, or talk exclusively about the macro- and micro-strategies, but also to analyse the transcripts and reveal differences and/or similarities between $\mathrm{A}_{1}$ and $\mathrm{A} 2$, as facilitated by the first and the second compliment, respectively.

\subsection{Macro strategies in $\mathrm{R} 1$ and $\mathrm{R} 2$}

The analysis shows that, in their first response, subjects largely resort to acceptance strategies, whereas in their second response, they employ nonacceptance strategies (among which evasion and reciprocating were more obvious). Table 1 summarises the overall results, based on Holmes's (1988) and Herbert's (1990) classification systems:

The subjects used appreciation tokens such as 'thank you' or one of its derivations most frequently as an acceptance strategy. With regard to nonacceptance macro level, the subjects used micro strategies such as shift credit ('my brother gave it to me'), humour ('I can sell it to you $20 \%$ off'), reciprocating ('so's yours'), and evasion ('don't mention'). By nonagreement, the subjects referred to strategies as disagreement ('you have not seen the other side of me'), qualification or mild

6. Cronbach's alpha is a tool to measure the internal consistency, that is, how closely related a set of items are as a group. 
Table 1. The frequency of responses ( $1 \& 2$ ) given to compliments

\begin{tabular}{lccc}
\hline Macro strategy & Response 1 & Response 2 & total \\
\hline Acceptance & $81(51 \%)$ & $32(20 \%)$ & 113 \\
Nonacceptance & $18(11 \%)$ & $60(37 \%)$ & 78 \\
Nonagreement & $5(3 \%)$ & $48(30 \%)$ & 53 \\
(Insincere) Request interpretation & $54(34 \%)$ & $12(8 \%)$ & 66 \\
No acknowledgement & $2(1 \%)$ & $8(5 \%)$ & 10 \\
total & $\mathbf{1 6 0}$ & $\mathbf{1 6 0}$ & $\mathbf{3 2 0}$ \\
\hline
\end{tabular}

disagreement ('it's alright, but it is not that much nice'), question ('is that so?'), and scale down ('it's really quite old'). Request interpretation ('you wanna borrow this one too?') and no acknowledgement (i.e., when there is no reaction to a compliment) are also observed among the subjects. Because the aim of this study is to investigate $\mathrm{C}_{1}$ and $\mathrm{C}_{2}$ based on the relevant appraisals, I am not going to have an in-depth analysis of the micro strategies.

\subsection{Compliment 1 and appraisal 1}

Contrary to the claim that Iranian people would mostly deny or downgrade a compliment because of cultural concept of shekasteh-nafsi (cf. Sharifian 2005), the results of this study reveal that Persian speakers' appraisal of the first compliment appeared mostly to be of the acceptance type. The results show that most of the subjects use short acceptance responses such as [mot æækeræm] (thank you), [mæmnu:n] (thanks), or [mersi: $]^{7}$ (thanks) to show acceptance. However, this short acknowledgement is not a genuine acceptance of the compliment, but rather an acknowledgement of the complimenter's positive face wants (which is called adab va ehteram ${ }^{8}$ in Persian culture). In fact, this kind of acceptance is at the service of the concept of shekasteh-nafsi, since 'mot $\int æ k e r æ m$ ' and 'mersi:' are prefabricated polite phrases, only produced to acknowledge the complimenter's need to be accepted. In other words, the subjects use short acceptance responses to show adab va ehteram as a reaction to a compliment. The acceptance is not considered as a sign of pride among Iranian speakers, but rather a politeness strategy to respect the complimenter's positive face. From the total number of

7. This is borrowed from French, meaning 'thanks' among Persian speakers.

8. According to Sharifian $(2011,106)$, 'adab va ehteram' are "roughly glossed as 'courtesy and respect' in English", which "encourages Iranians to constantly place the presence of others at the centre of their conceptualizations and monitor their own ways of thinking and talking to make them harmonious with the esteem that they hold for others." 
acceptances in $\mathrm{R} 1(n=81)$, in 73 cases, the appreciation tokens were accompanied by a second assessment through nonagreement or nonacceptance. Therefore, the complimentee's acceptance of the compliment is not a sign of self-praise, but rather an approval of the complimenter's positive face through providing appreciation tokens such as 'thank you'. Since Persian speakers are highly sensitive to other's face wants in line with their traditional and conservative culture (if not, they might be accused of being impolite), they do not convey shekasteh-nafsi by directly rejecting or denying a compliment ${ }^{9}$ (it is against their cultural schema of adab va ehteram). Direct rejecting is regarded as impolite and embarrassing among Persian speakers (Izadi and Zilaie 2015), and thus, challenges interlocutors' positive face wants. The data indicate that using 'thank you' is an indirect way of rejecting, considering the accompanied second assessment of the first compliment which is mostly 'nonagreement' or 'nonacceptance'. As the data reveal, in most cases, the first compliment is appraised as insincere ${ }^{10}$ praise, a politeness strategy, or phatic communication. The response to this appraised insincere compliment is mostly a short positive acknowledgement (which is also an insincere acceptance strategy). Since the first compliment is appraised as a phatic communication, rejection is considered a face-threatening behaviour. The following cases are extracts from the transcripts dealing with the context of the first compliment and the first response. The provision of the second compliment and the second response is discussed in the next section ( $\mathrm{A}$ is the complimenter and $\mathrm{B}$ is the complimentee):

(1) A: rbrstir, tfe xoebcer fode?

truly, what news became?

By the way, what is going on?

A: musho:t xejli: Geefeng fode emruiz.

hair+your very beautiful become+has today.

Your hair is very beautiful today.

B: moemnu:n, teefwit Goefong mirbirne.

thank you, eyes+your beautiful see.

Thank you, beauty is in the eye of the beholder.

A: mжтnu:n.

thank you.

Thank you.

9. Sharifian (2005) claims that Persian speakers show shekasteh-nafsi through denying or downplaying a compliment.

10. By 'insincere', I do not intend to say that something done for the sake of politeness is necessarily insincere. I simply mean that the first compliment is not appraised as a genuine compliment. 
The above response (B) shows a common pattern among the subjects. The complimentee provides a short positive acknowledgement (mæmnuin), meaning thank you, as their first appraisal. This first assessment is mostly an automatic response. Provided that the compliment respects ethical and cultural conventions, the common appraisal is mostly a short appreciation token. In other words, the common appraisal of the first compliment is that the compliment is insincere, a politeness strategy. On this account, the answer is also insincere. That is not the end of the story. Since a brief response such as 'thank you' may endanger smooth communication (it may be regarded as a sign of dissatisfaction among Persian speakers), the complimentee provides a second assessment of the compliment by providing a longer sentence as a complement of the brief response. In (1), [t $\int \mathrm{e} \int \mathrm{b}$ : Gæ\{æng mibbine], meaning 'beauty is in the eye of the beholder', is a prefabricated response, a politeness strategy that returns the compliment to the complimenter.

Moreover, it was frequently observed in the transcripts that in the second assessment, the complimentee uses the strategy of 'topic shift' as a sign of shekasteh-nafsi. They change the topic to shift the attention from themselves to the complimenter. The following conversation supports this claim:

(2) A: foermonde.

sorry+I+am.

I am sorry.

A: dir kæerdom, volir mesle homirfe soeburr hosti: to.

late was $+I$, but like always patient are you.

I was late, but you are patient like always.

B: mersir, no. xejli: dirr noju:moedir.

thanks, no. very late weren't+you.

Thanks, no, you weren't very late.

A: behorhwil, ozr mirxv:m.

to any condition, excuse I+want.

Anyway, excuse me.

B: bi: xirjp:l.

without thinking.

Don't think about it [anymore].

Conversation (2) reveals that 'topic shift' is a case of shekasteh-nafsi among Persian speakers, since the shift is made to downgrade the complimentary force of the compliment. As observed in (2), the first assessment is a brief response (mersi)). Nonetheless, the second assessment is not a prefabricated response. In (2), [næ, xejli: dirr næju:mædir], meaning 'you weren't very late', is a topic shift. This second assessment is a reaction to non-complimentary part of $\mathrm{C} 1$ that is [emruzz dirr kærdæm], meaning 'I was late today'. As discussed earlier, the first assessment is 
an ostensive appreciation token instead of rejection, which is a face-threatening act. Likewise, topic shift can be interpreted as indirect rejection, yet not a facethreatening act such as explicit rejection.

In attributes about possession, another complicated response is observed among the subjects' first appraisal of the first compliment, and that is [Gv:bel nædv:re], ${ }^{11}$ meaning 'it doesn't have value'. This phrase, obviously misused as a politeness strategy among the subjects, conveys an insincere offer. By analysing the etymology of the phrase [Gv:bel nædv:re], we can understand the mystery revolving around it. The term [Gv:bel] means 'value', and [nædv:re] means 'doesn't have'. As a comparison, the Persian expression [nv:gvibele] literally means 'it doesn't have any value'. Likewise, the phrase [Gvibel nædvire] means 'it doesn't have value'. According to data, this phrase is conventionally used as a response to a compliment about possession to mean (insincerely) 'you can have the complimented possession. ${ }^{12}$ Based on the illocutionary meaning of this phrase, the hearer is not expected to take the explicit meaning seriously. The data indicate that Persian speakers usually say [Gv:bel nædvrre] as an insincere offer (taarof) $)^{13}-$ a politeness strategy - while the literal meaning is 'it doesn't have value', in line with the meaning of its constituting parts. Then, if 'it doesn't have value', it must not be interpreted as 'you can have it'. In its current form, the literal meaning of [Gw:bel nædv:re] does not contribute to the concept of taarof. If, in response to 'what a beautiful watch', one says [Gvibel nædvre], this means that 'my watch doesn't have any value but I offer the watch to you and you can have it. Therefore, [Gv:bel nædv:re] literally conveys an impolite offer, but since many Persian speakers have conventionally used it as taarof, the phrase is viewed as a politeness strategy (therefore, politeness is both relational and conventional in this case). The apparent disjunction between the literal and the conventional meaning of [Gv:bel nædv:re] seems to be worked out in the interaction. The use of the phrase [Gvibel nædv:re] is shown in the following transcript:

11. I discuss later that this phrase is used incorrectly (with regard to syntax) among Persian speakers. By 'incorrectly', it means that the literal meaning of the phrase does not match with its illocutionary meaning. The correct form of this phrase should be [Gvibele fomv: ro nædvire], meaning 'you deserve more'.

12. Imagine a situation in which a Persian speaker compliments her friend by saying 'what a nice phone. The receiver of the compliment then replies [Gv:bel nædv:re]. This phrase is conventionally used among Persian speakers as a strategy of taarof, meaning you can have this phone if you like', while the literal meaning is 'it doesn't have any value.' The contradiction is easily observable.

13. Sharifian argues that taarof or tarof is conceptualised in the form of "ostensible invitations, repeated rejection of offers, insisting on making offers, hesitation in making requests, giving frequent compliments, hesitation in making complaints, etc." $(2010,446)$. 
(3) A: cedzoeb gurfirje Geefongi:

what phone+a beautiful.

What a beautiful phone!

B: momnu:n, Go:bel noedv:re.

thanks, value doesn't+have.

Thanks, it doesn't have any value.

A: svihebef lvizem dorre.

owner+its need has.

Its owner needs it.

In (3), B shows a contradiction between the literal and the illocutionary meaning of [Gr:bel]. If we accept that [Gr:bel] means 'value', then we should use [Gv:bele Somv: ro nædv:re], meaning 'it doesn't have any value for you, thus, you deserve more', instead of [Gv:bel nædv:re]. Based on the findings, it is clear that most Persian speakers subconsciously misinterpret [Gv:bele Jomv: ro nædv:re] as a strategy of taarof (you can have it), yet this phrase should be interpreted as 'you deserve more and this object is not good enough for you'. This interpretation is more polite than interpreting it as 'it doesn't have any value for you, and you can have it', which is germane to the concept of shekasteh-nafsi, not taarof. However, the data show that the subjects interpret [Gvibele fomv: ro nædvire] as taarof, meaning: 'You deserve more and/but I offer you to keep this as a gift'. Arguing that [Gv:bele fomv: ro nædv:re] is a kind of taarof, one may interpret the phrase ironically, regarding the fact that we should not offer an object to someone when we think they deserve a better object than the one we have. The argument can be put forward as follows:

- Speakers (conventionally) use [Gvibel nædv:re] to mean x;

- The literal meaning of the words is $y$;

- However, the speakers' appraisal is $\mathrm{x}$.

In (3), the complimentee has used the word [mæmnuin] - seemingly a positive response, but in effect, a politeness strategy. If it was an acceptance strategy, the complimenter would not have said [Gv:bel nædv:re] as the second assessment. Therefore, if it was a positive appraisal of the compliment, the second assessment of the compliment should have complemented the first one. Combining the first and the second part of the response in (3), it can be understood that B means 'thank you for complimenting me' but 'my phone doesn't have value' (shekasteh$n a f s i$ ). If we interpret (mæmnu:n) as a sign of self-praise, the first assessment (mæmnu:n) and the second assessment (Gv:bel nædv:re) are not related to one other, and hence contradictory. 
By uttering [Gv:bel nædv:re], the complimentee shifts the attention from the compliment to a provision of responding to [Gv:bel nædv:re]. ${ }^{14}$ Phrases such as [Gb:bel nædv:re] or [Gv:bele fomv: ro nædv:re] require a response on the part of the complimenter. The response to [Gv:bel nædv:re] is shown in conversation (4):

(4) A: oedzoeb gu:firje Goesongi:.

What a beautiful phone.

B: momnu:n, Gribel noedvire.

Thanks, it doesn't have value [conventionally means you can have it as a gift].

A: lotf dv:ris.

It's kind of you.

With regard to (4), using [mæmnuin] or [lotf dvrri:], meaning 'it is kind of you', in response to [Gv:bel nædv:re] shows that the complimenter conventionally considers the phrase as taarof. ${ }^{15}$ If Response 1 uses [Gv:bele fomv: ro nædv:re], which is the correct form, then 'thank you' would be a logical response. Moreover, responses such as [dorurd be to] (peace be upon you) or [bozorgvirii:] (you are great) were reported by the subjects.

It was frequently observed among the subjects that A1 consists mostly of a two-part response. The first part is the acknowledgement of the compliment, and this acts as a politeness strategy (not a genuine acceptance of the compliment). On the other hand, brief responses such as [mersi:] and [mæmnu:n] are not effective responses for the development of the flow of communication among Persian speakers. Cheng $(2011,2211)$ states that "overtly brief responses, such as a simple 'thank you', might put the interlocutor in an uncomfortable position and cause potential difficulties for smooth communicative progress." To recap, the shorter part of the response deals with the acknowledgement of the compliment, whereas the longer part of the response works as a social lubricant, or as a complement of the first part.

14. This is a very perplexing and mysterious phrase. One can hardly make an exact translation of [Gv:bel nædv:re] to other languages. It is another example of the prefabricated responses observed among Persian speakers. The literal meaning of this phrase is that the object being complimented 'does not have any value.' However, the speaker conventionally offers this 'valueless' object to the complimenter as a gift.

15. The error of 'function shift' has happened in this case; [Gv:bele fomv: ro nædv:re] is a strategy of shekasteh-nafsi, although many Persian speakers consider this phrase or [Gv:bel nædv:re] as taarof which is clearly wrong. The true interpretation of [Gv:bele fomv: ro nædvire] is 'you deserve more', and that this object is valueless. Therefore, phrases such as [Gvibele fomv: ro nædv:re] or [Gv:bel nædv:re] are 'downgrading' strategies and should not be regarded as taarof, but rather, as shekasteh-nafsi. 


\subsection{Compliment 2 and appraisal 2}

It was argued in the foregoing section that $\mathrm{A}_{1}$ is largely automatic (of course, I am not sure whether I can generalise this premiss to non-friends or complete strangers). The results of this study show that the subjects rarely consider the first compliment as genuine praise, and thus, they provide an automatic insincere response as a politeness strategy. In the next stage, the research assistant provided the second compliment with a short delay after the first compliment to make the second compliment seem more natural. The aim of the second compliment was to elicit the complimentee's response based on a second appraisal of the event. The following transcripts are from the same interactions as presented in the previous section, but here only Compliment 2 and Response 2 are presented:

(5) $[\ldots]$

A: irn model mu: vorgean behet mirjo:d.

this style hair really to+you come.

This hairstyle really suits you.

B: bo:z tfir mixxij emruizoez mon?

again what want+you today from me?

What are you complimenting me for, again?

A: burver kon dzedir mirgem.

believe do serious say+I.

Believe me, I am serious.

B: doefeje pirfke puil oezom gorz kordirjo:dete? situation last that money from + me borrow did remember+you? Can you remember the last time you borrowed money from me?

Conversation (5) shows that the complimentee (B) does not feel satisfied with the second compliment. I would argue that what is crucial here is that the first compliment is part of expected behaviour (i.e., a compliment as phatic to open conversation) that requires an expected pleasant response. However, the same compliment later in the conversation must be a sign that the complimenter has an ulterior motive since later in the conversation is not the place for a phatic opening remark. The word [bv:z] meaning 'again' shows that the complimenter has had an unpleasant experience of being complimented by his/her conversational partner in the past (the complimenter has borrowed some money from the complimentee). Using this phrase [ $\mathrm{t}$ ji: mixxvij emruzz æz mæn?], meaning 'what are you complimenting me for', reveals that the compliment is appraised as flattery or as a prelude to an unpleasant request from the complimenter.

In (6), another rather complicated prefabricated phrase as [xw:hef mikkonæm], which literally means 'please', is observed among the subjects. This 
phrase has many functions based on contextual factors. One of its common meanings is 'please', as a polite way of addressing someone to do something. For instance, one may say [xv'he mikonæm befini:d], meaning 'please sit down'. Another meaning is to 'beg someone', used when someone is asking others politely to accept his/her offer. The sentence [xv:he J mirkonæm mæno bebæx]] meaning 'I beg you to forgive me' is an example in this case. More often than not, however, the subjects used [xvihe $\int$ mi:konæm] as a conventional way to indicate shekastehnafsi. On this account, this modest use of [xv'he $\int$ mikonæm] means 'don't mention it' or 'it wasn't a big deal'. Moreover, the complimentee says [rorsti:, dv:nejkæde ræfti:?] which means 'by the way, did you go to the faculty?' as an attempt to shift the complimenter's attention away from the earlier compliment. In the following conversation, this last meaning is applied to the phrase. Accordingly, this phrase is a downgrading strategy:

(6) $[\ldots]$

A: kv:f home mesle to sobuir bu:don.

I+wish everyone like you patient was.

I wish everyone was patient like you.

B: xw:he mi:konom, lotf dviri:

beg do+I, kindness have+you.

Don't mention it (please), it is kind of you.

B: rorstir, dwinefkcede roeftir?

truly, faculty went+you?

By the way, did you go to the faculty?

A: no, bv: hoem mirrism.

no, with together go+we.

No, we go together.

In (6), the phrase [lotf dv:rir], meaning 'it is kind of you', is another prefabricated response that acts as a reciprocating strategy, inasmuch as it returns the compliment to the complimenter. The following example is another case that shows the complexities of the Persian speakers' second appraisals:

(7) $[\ldots]$

A: gu:firt xejlirfirke.

phone+your very chictis.

Your phone is very chic.

B: noe bvibvi, uingaedoem Geefong nist.

no daddy, that + much beautiful is+not.

I don't agree with you, it is not that much beautiful. 
A: tferb:, Gaefenge. Jekxeste-nafsi: noekon. yes, beautifultis. modesty don't + do. Yes, it is beautiful. Don't be so modest.

The extract manifested in ( 7 ) justifies the important role of context in interpreting the meaning of culturally-loaded phrases. The phrase [næ bv:bv:] is a case in point. It has different meanings based on the context. The literal meaning of [næ bv:bv:] is 'no daddy', but this meaning does not make sense in (7). Another meaning of [næ bv:bv:] is 'no way' - with a rising intonation - which acts as an interjection. This kind of interpretation is usually accompanied by facial expressions showing surprise. Another interpretation of this phrase is to show a mild disagreement (with a falling intonation). In other words, [næ bv:bv:] is less facethreatening than 'I don't agree.' This third interpretation is exemplified by the CR exchange in (7). In fact, [næ bv:bv:], meaning 'I don't agree', and [urngædæm Gæ\{æng nirst], meaning 'it is not that much beautiful', complement each other perfectly. Overall, Table 2 summarises the most common phrases used by the subjects as a response to compliments:

Table 2. Common phrases observed in subjects' responses to compliments

\begin{tabular}{|c|c|c|c|c|}
\hline Phrase & $\begin{array}{l}\text { Micro } \\
\text { strategy }\end{array}$ & $\begin{array}{l}\text { Observed } \\
\text { frequency }\end{array}$ & Function & Conventional meaning \\
\hline mæmnu:n & $\begin{array}{l}\text { Appreciation } \\
\text { token }\end{array}$ & 31 & $\begin{array}{l}\text { Adab va } \\
\text { ehteram }\end{array}$ & Thanks. \\
\hline motfækeræm & $\begin{array}{l}\text { Appreciation } \\
\text { token }\end{array}$ & 12 & $\begin{array}{l}\text { Adab va } \\
\text { ehteram }\end{array}$ & Thanks. \\
\hline 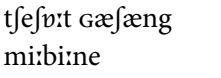 & Reciprocation & 8 & $\begin{array}{l}\text { Shekasteh- } \\
\text { nafsi }\end{array}$ & $\begin{array}{l}\text { Beauty is in the eye of the } \\
\text { beholder. }\end{array}$ \\
\hline mersi: & $\begin{array}{l}\text { Appreciation } \\
\text { token }\end{array}$ & 45 & $\begin{array}{l}\text { Adab va } \\
\text { ehteram }\end{array}$ & Thanks. \\
\hline Gv:bel nædv:re & Downgrading & 18 & Taarof $^{*}$ & You can have it as a gift. \\
\hline xv:he $\int$ mi:konæm & Downgrading & 19 & $\begin{array}{l}\text { Shekasteh- } \\
\text { nafsi }\end{array}$ & It's not a big deal. \\
\hline lotf dv:ri: & Reciprocating & 11 & $\begin{array}{l}\text { Shekasteh- } \\
\text { nafsi }\end{array}$ & It's kind of you. \\
\hline næ bv:bv: & Qualification & 6 & $\begin{array}{l}\text { Shekasteh- } \\
\text { nafsi }\end{array}$ & I don't think so. \\
\hline
\end{tabular}

${ }^{\star}$ I argued that the subjects conventionally use this phrase as taarof while it literally conveys shekasteh-nafsi.

The results of this study revealed that the responses to the first compliments are mostly automatic reactions which are largely sympathetic towards face- 
enhancement and politeness works. Therefore, the first response is largely a social act that is based on Sperber and Wilson's (1986) 'principle of economy' whereby the response is justified in accord with the most easily accessible reaction to the compliment. On the other hand, the second response is more controlled where the reaction is not only based on the economy principle but one that is anchored in strategic choices and idiosyncrasies of the situation which require more cognitive efforts. In responding to the second compliment, the complimentees resorted to conscious processes in line with their appraisal of the compliment to figure out the illocutionary force of the second compliment. In this regard, as reported by Mazzone $(2013,454)$, "conscious control appears to be occasionally required in the course of action when smooth automatic processing fails."

\section{Discussion}

The findings reinforced the idea that the second appraisal of the second compliment is different from the first appraisal of the first compliment. The first appraisal is usually automatically generated (51\% of the participants used acceptance strategies) in line with the cultural schema of adab va ehteram, and the short appreciation token is usually insincere and a sign of politeness (not a real acceptance). The first compliment is appraised as a 'social lubricant' to give face to interlocutors. Therefore, in most cases, a short response such as 'thank you' suffices. However, since a brief response may endanger smooth conversation, the complimentee uses a second somewhat longer response, attached to appreciation tokens, to convey (maybe insincerely) the feeling that $s /$ he is happy with the compliment. As for the second appraisal of the second compliment, the data reveal that most of the subjects use more downgrading or denying strategies than appreciation tokens (37\% used nonacceptance and 30\% resorted to nonagreement strategies). On this account, the second appraisal is not automatically generated since a second compliment of the same attribute is not appraised as a politeness strategy among Persian speakers. The second compliment is mostly appraised with a downgrading or disagreement response to show that the complimentee is unhappy with or feels embarrassed about the praise. Generally speaking, the second compliment may be appraised as sarcasm, flattery, or the possibility of an unpleasant request from the complimenter. Figure 2 shows the interaction between the sociocognitive elements of the CR exchanges among the subjects.

Figure 2 indicates that the subjects' value-sets are in conflict, in that Response 1 and Response 2 are largely contradictory with regard to the fact that they are associated with different emotional stance (emotional involvement). Appraisal 1 tells the complimentee that the compliment is a politeness strategy and should 


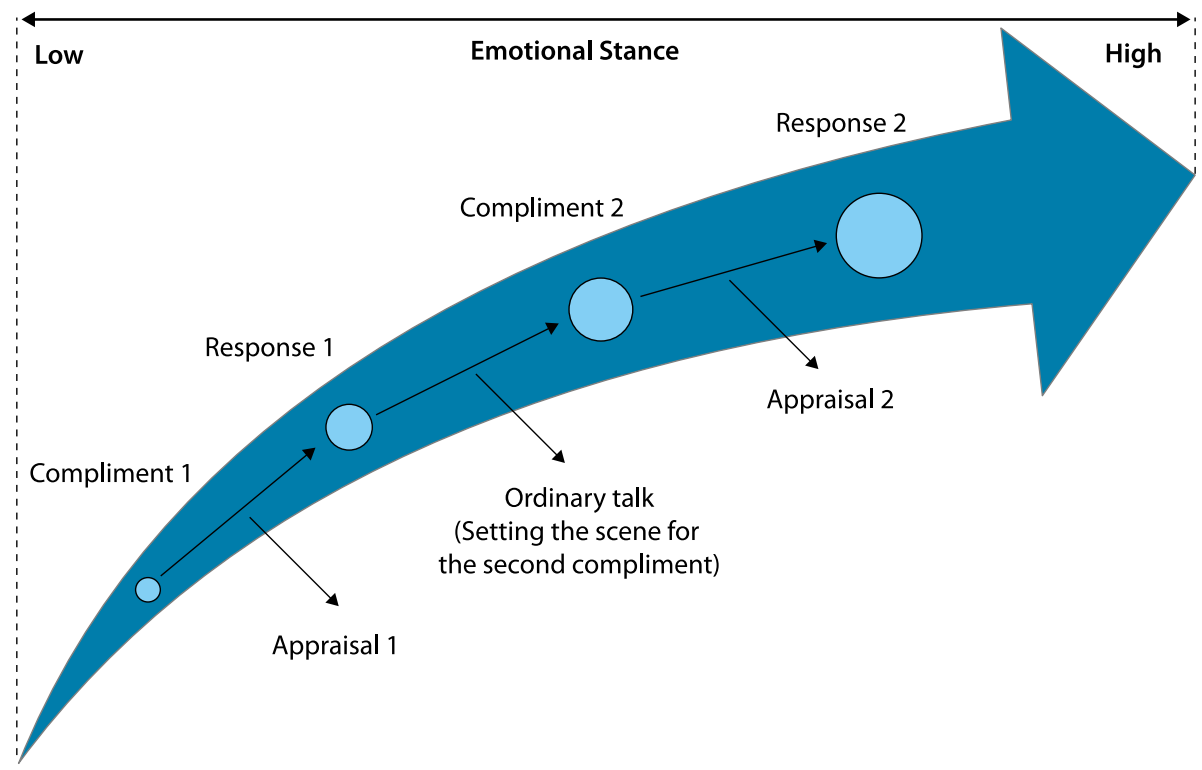

Figure 2. The CR exchanges and the emotional stance (emotional intensity)

be (insincerely) accepted to respect the complimenter's positive face wants. On the contrary, A2 acts as a warning. The appraisal system considers $\mathrm{C}_{2}$ with more deliberation and forces the individual to understand the (hidden) conversational role and the illocutionary force of the $\mathrm{C}_{2}$. Since a second compliment on the same attribute is not what would normally be expected, a conflict in value-sets may arise. This conflict requires a non-automatic response to ward off the consequences of accepting the perlocutionary effect ${ }^{16}$ of the second compliment. The compliment may be negatively appraised and, therefore, negatively responded to.

The results of this study point out that the CR exchanges are cases of a complex language game among Persian speakers. The data reveal that Persian speakers usually appraise the first compliment as insincere, but that cultural conventions force them to acknowledge the first compliment as a social lubricant and thus provide a short response to respect the positive face of the complimenter. In other words, they do not deny or downgrade a compliment by referring to nonacceptance or disagreement strategies, as is claimed by researchers such as Sharifian (2005). Sharifian says that most Persian speakers tend to deny or downplay a compliment (elicited by a DCT) in line with the Iranian cultural concept shekasteh-nafsi. Although it is true that Persian speakers try to represent a humble

16. Perlocutionary acts are viewed at the level of their consequence, such as convincing, persuading, enlightening, scaring, inspiring, or otherwise affecting the listener (Austin 1962). 
culture, they do not deny or reject a compliment directly, since this would threaten the complimenter's positive face wants. In consonance with Myers (1991), disagreements can carry possible threats to individuals' positive face. Providing a short acceptance response is, in fact, a way to acknowledge the compliment (which is not a sign a self-praise); but since this short response may endanger smooth communication, Persian speakers mostly attach a second response (which is mostly a downgrading strategy) to a brief acknowledgement, serving to contribute to the flow of conversation. What Sharifian's (2005) study fails to consider is that, for most Iranians, complimenting is just a politeness strategy and is rarely regarded as a genuine act of praising the talent, beauty, or a positive feature of the receiver of the compliment. On this account, the first compliment is largely regarded as phatic communication, a social lubricant to be precise (therefore, the complimentee would accept the first compliment influenced by Iranian cultural schema of adab va ehteram). It is true that Persian speakers convey humbleness or shekasteh-nafsi in their responses to compliments, but this does not mean that Persians convey humbleness through direct rejection of a compliment (a brief acceptance note such as 'thank you' can be an indicator of shekasteh-nafsi).

That said, the second compliment on the same attribute is a different case. The illocutionary force of the second compliment is rarely acknowledged as a social lubricant (since the interaction has already opened up). The second compliment requires more cognitive processes since it is unexpected or rarely expected. First compliments are cases of phatic communication and are more or less automatically responded to. Second compliments, on the other hand, are neither expected nor connected to politeness. Consequently, it can be concluded that Persian speakers are adaptive with regard to the second and maybe the third compliments. Persian speakers are adaptive since their minds can distinguish between compliments that require automatic processing and those which need more complex cognitive/controlled processes during the CR exchanges.

\section{Conclusion}

Overall, the results of this study suggest that Iranian people were strategic (referring to automatic and controlled responses) in responding to compliments, which indicates that they may change the conventional rules in line with their appraisals of the events, or as a consequence of self-interest channelled through a second appraisal of the second compliment. For instance, the data from this study point out that Iranian people are sometimes modest and sometimes manipulative. This is justified based on individuals' appraisals of the compliments given in sequence. In this regard, Bagozzi et al. $(1999,33)$ state that "when asked how one feels at 
present, people respond in accordance with their own unique feelings which are the outcomes of appraisals of heterogeneous sources." Bagozzi et al. continue that "[p]eople will differ in intensity of felt affect but will interpret this in the light of their cultural world views and knowledge of their own emotions" (1999, 33).

The results of this study generated some contradictions. Unlike the view endorsed by Golato $(2005,170)$, that the first and the second assessment of a compliment are uttered in conjunction with each other, the results of this study show that the first and the second assessment of a compliment can be contradictory. The results of this study seem to refute the argument made by Ahmadi and Ahmadi $(1998,110)$, who claim that "in Iranian society, there is a tight bond between the good of oneself and of the others." I counter argue this by stating that this bond is not a tight one, but one that is based on the Iranian cultural schema of taarof or insincere offer. The findings of this study proved that when a speaker suspects that his/her self-interest is at stake (e.g., expects that the complimenter might make an unpleasant request through an appraised insincere compliment), the conversation becomes serious and the complimentee ignores taarof and shekasteh-nafsi in an attempt to protect his/her own self-interest. Iranian people's 'goodness towards others' is different from their 'goodness towards the self', as the former is mostly a matter of politeness (it may not be a sincere feeling towards others).

In short, Weigand $(2010,93)$ is right when she says "[h] ow self-interest and respect are balanced in the mixed game depends on the individual's mind as well as on cultural ideology." Accordingly, to come up with a sound conceptualisation of compliment in the course of interaction, both cognitive and social factors should be taken into consideration. It is interesting that other researchers, such as Weigand, have also pointed to the sociocognitive nature of interaction in delineating the broad scope of discourse and the power of individuals as manipulative agents.

\section{References}

Ahmadi, Nader, and Fereshteh Ahmadi. 1998. Iranian Islam: The Concept of the Individual. London: MacMillan. https://doi.org/10.1057/9780230373495

Allami, Hamid, and Maryam Montazeri. 2012. "Iranian EFL Learners' Compliment

Responses." System 40 (4): 466-482. https://doi.org/10.1016/j.system.2012.10.010

Ansarin, Ali Akbar, and Mostafa Morady Moghaddam. 2016. "Complimenting Functions by

Native English Speakers and Iranian EFL Learners: A Divergence or Convergence?"

Applied Research on English Language 5 (1): 51-76.

Austin, John Langshaw. 1962. How to Do Things with Words. Oxford: Oxford University Press. 
Bagozzi, Richard P., Nancy Wong, and Youjae Yi. 1999. "The Representation of Affect in Independent- and Interdependent-based Cultures." Cognition and Emotion 13: 641-672. https://doi.org/10.1080/026999399379023

Bardovi-Harlig, Kathleen, and Beverly S. Hartford. 2005. Intercultural Pragmatics: Exploring Institutional Talk. Mahwah: Lawrence Erlbaum Associates. https://doi.org/10.4324/9781410613776

Cheng, Dongmei. 2011. "New Insights on Compliment Responses: A Comparison between Native English Speakers and Chinese L2 Speakers.” Journal of Pragmatics 43 (8): 2204-2214. https://doi.org/10.1016/j.pragma.2011.02.003

Danziger, Roni. 2018. "Compliments and Compliment Responses in Israeli Hebrew: Hebrew University in Jerusalem Students in Interaction." Journal of Pragmatics 124: 73-87. https://doi.org/10.1016/j.pragma.2017.12.004

Farghal, Mohammed, and Mahmoud A. Al-Khatib. 2001. “Jordanian College Students' Responses to Compliments: A Pilot Study." Journal of Pragmatics 33: 1485-1502. https://doi.org/10.1016/S0378-2166(01)00oo6-6

Golato, Andrea. 2002. "German Compliment Responses." Journal of Pragmatics 34: 547-571. https://doi.org/10.1016/S0378-2166(01)00040-6

Golato, Andrea. 2005. Compliments and Compliment Responses: Grammatical Structure and Sequential Organization. Amsterdam: John Benjamins. https://doi.org/10.1075/sidag.15

Goodwin, Marjorie H., Asta Cekaite, and Charles Goodwin. 2012. "Emotion as Stance." In Emotion in Interaction, ed. by Marja-Leena Sorjonen, and Anssi Peräkylä, 16-41. Oxford: Oxford University Press. https://doi.org/10.1093/acprof:oso/9780199730735.003.0002

Heidari, Mohammad A., Mohsen Rezazadeh, and A. Eslami Rasekh. 2009. "A Contrastive Study of Compliment Responses among Male and Female Iranian Teenage EFL Learners." The International Journal of Language, Society and Culture 29: 18-31.

Herbert, Robert K. 1990. "Sex-based Differences in Compliment Behaviour." Language in Society 19: 219-224. https://doi.org/10.1017/So047404500014378

Holmes, Janet. 1988. “Paying Compliments: A Sex-preferential Politeness Strategy. Journal of Pragmatics 12 (4): 445-465. https://doi.org/10.1016/0378-2166(88)90005-7

Izadi, Ahmad, and Farzaneh Zilaie. 2015. "Refusal Strategies in Persian." International Journal of Applied Linguistics 25 (2): 246-264. https://doi.org/10.1111/ijal.12065

Karimnia, Amin, and Akbar Afghari. 2011. "Compliments in English and Persian Interaction: A Cross-cultural Perspective." Jezikoslovije 12 (1): 27-50.

Kasper, Gabriele. 2008. “Data Collection in Pragmatics Research.” In Culturally Speaking: Culture, Communication and Politeness Theory, ed. by H. Spencer-Oatey, 279-303. London: Continuum.

Lombardi Vallauri, Edoardo. 2016. "Implicits as Evolved Persuaders." In Pragmeme and Theories of Language Use, ed. by K. Allan, A. Capone, and I. Kecskes, 725-748. Cham: Springer. https://doi.org/10.1007/978-3-319-43491-9_36

Lorenzo-Dus, N. 2001. "Compliment Responses among British and Spanish University Students: A Contrastive Study." Journal of Pragmatics 33: 107-127. https://doi.org/10.1016/So378-2166(99)00127-7

Maíz-Arévalo, Carmen. 2012. ““Was that a Compliment?” Implicit Compliments in English and Spanish." Journal of Pragmatics 44 (8): 980-996.

https://doi.org/10.1016/j.pragma.2012.04.004 
Mazzone, Marco. 2013. “Automatic and Controlled Processes in Pragmatics." In Perspectives on Linguistic Pragmatics, ed. by A. Capone, F. Lo Piparo, and M. Carapezza, 443-468. Cham: Springer. https://doi.org/10.1007/978-3-319-01014-4_18

Mey, Jacob L. 2001. Pragmatics. Oxford: Blackwell.

Mohajernia, Reza, and Hassan Solimani. 2013. "Different Strategies of Compliment Responses Used by Iranian EFL Students and Australian English Speakers." Journal of Language Teaching and Research 4 (2): 340-347. https://doi.org/10.4304/jltr.4.2.340-347

Morady Moghaddam, Mostafa. 2017. "Politeness at the Extremes: Iranian Women's Insincere Responses to Compliments." Language and Dialogue 7 (3): 414-432.

Motaghi-Tabari, Shiva, and Louise de Beuzeville. 2012. "A Contrastive Study of Compliment Responses among Persian and Australians: The Effects of Exposure to a New Speech Community." Applied Research in English 1 (1): 21-42.

Mustapha, Abolaji Samuel. 2011. "Compliment Response Patterns among Speakers of Nigerian English.” Journal of Pragmatics 43: 1335-1348. https://doi.org/10.1016/j.pragma.2010.10.025 Myers, Greg. 1991. "Politeness and Certainty: The Language of Collaboration in an Al Project." Social Studies of Science 21 (1): 37-73. https://doi.org/10.1177/030631291021001004

Nkwain, Joseph. 2011. "Complimenting and Face: A Pragma-stylistic Analysis of Appraisal Speech Acts in Cameroon Pidgin English." Acta Linguistica Hafniensia 43 (1): 60-79. https://doi.org/10.1080/03740463.2011.589992

Ochs, Elinor. 1996. “Linguistic Resources for Socializing Humanity.” In Rethinking Linguistic Relativity, ed. by John J. Gumperz, and Stephen C. Levinson, 407-437. Cambridge: Cambridge University Press.

Pomerantz, Anita. 1978. "Compliment Responses: Notes on the Co-operation of Multiple Constraints." In Studies in the Organization of Conversational Interaction, ed. by Jim Schenkein, 79-112. New York, San Francisco, London: Academic Press. https://doi.org/10.1016/B978-0-12-623550-0.50010-0

Razmjoo, Seyyed Ayatolla, Elyas Barabadi, and Ali Arfa. 2013. "An Investigation into the Speech Act of Compliment Response in Persian." International Journal of Applied Linguistics and English Literature 2 (1): 44-52. https://doi.org/10.7575/ijalel.v.2n.1p.44

Rees-Miller, Janie. 2011. "Compliments Revisited: Contemporary Compliments and Gender." Journal of Pragmatics 43 (11): 2673-2688. https://doi.org/10.1016/j.pragma.2011.04.014 Roseman, Ira J., and Craig A. Smith. 2001. "Appraisal Theory: Overview, Assumptions, Varieties, Controversies.” In Appraisal Processes in Emotion, ed. by Klaus R. Scherer, Angela Schorr, and Tom Johnstone, 3-20. Oxford: Oxford University Press.

Sadeghi, Elahe, and Gholam Reza Zarei. 2013. "Investigating the Use of Compliments in Persian and English: A Case Study of Iranian EFL Students." Journal of Foreign Language Teaching and Translation Studies 2 (2): 30-49.

Scarantino, Andrea. 2016. "The Philosophy of Emotions and its Impact on Affective Science." In Handbook of Emotions (fourth edition), ed. by Lisa Feldman Barrett, Michael Lewis, and Jeannette M. Haviland-Jones, 3-48. New York, London: The Guilford Press.

Schneider, Walter, and Richard M. Shiffrin. 1984. "Automatic and Controlled Processing Revisited.” Psychological Review 91 (2): 269-276. https://doi.org/10.1037/0033-295X.91.2.269

Sharifian, Farzad. 2005. "The Persian Cultural Schema of Shekasteh-nafsi: A Study of Compliment Responses in Persian and Anglo-Australian Speakers." Pragmatics \& Cognition 13 (2): 337-361. https://doi.org/10.1075/pc.13.2.05sha 
Sharifian, Farzad. 2010. "Semantics and Pragmatic Conceptualizations within and Emerging Variety: Persian English." In The Routledge Handbook of World Englishes, ed. by

Andy Kirkpatrick, 442-456. London: Routledge.

Sharifian, Farzad. 2011. Cultural Conceptualisations and Language: Theoretical Framework and Applications (Vol. 1). Amsterdam: John Benjamins. https://doi.org/10.1075/clscc.1

Sperber, Dan, and Deirdre Wilson. 1986. Relevance. Oxford: Blackwell.

Tang, Chen-Hsin, and Grace Qiao Zhang. 2009. "A Contrastive Study of Compliment

Responses among Australian English and Mandarin Chinese Speakers." Journal of

Pragmatics 41: 325-345. https://doi.org/10.1016/j.pragma.2008.05.019

Weigand, Edda. 2010. Dialogue: The Mixed Game. Amsterdam: John Benjamins.

https://doi.org/10.1075/ds.10

Wittgenstein, Ludwig. 1953. Philosophical Investigations. Oxford: Blackwell.

Yousefvand, Zohreh. 2010. "Study of Compliment Speech act Realization Patterns across

Gender in Persian.” Arizona Working Papers in SLA \& Teaching 17: 91-112.

\section{Address for correspondence}

Mostafa Morady Moghaddam

Shahrood University of Technology

Department of English

Shahrood

PoBox: 3619995161

Iran

mmoghaddam@shahroodut.ac.ir

\section{Biographical notes}

Mostafa Morady Moghaddam is an Assistant Professor at Shahrood University of Technology, Shahrood, Iran. Mostafa does research on discourse analysis, pragmatics and cultural linguistics as related to different settings and contexts, including language learning. His most recent publications are published in 'Lingua' and 'Language and Dialogue'. His recent monograph on 'indirect reports' is under production by Springer.

https://orcid.org/oooo-0002-7939-7105

\section{Publication history}

Date received: 15 March 2018

Date accepted: 27 November 2018

Published online: 18 June 2019 